\title{
The barriers that women face when choosing food for their primary school children: A case study in the Western Cape Province, South Africa
}

\author{
Y Smit, ${ }^{1}$ BSc, M Nutr; S Kassier, ${ }^{2} \mathrm{PhD} ;$ D Nel, ${ }^{3} \mathrm{PhD}$; N Koen, ${ }^{1} \mathrm{BSc}, \mathrm{M}$ Nutr \\ ${ }^{1}$ Division of Human Nutrition, Faculty of Medicine and Health Sciences, Stellenbosch University, Cape Town, South Africa \\ ${ }^{2}$ Dietetics and Human Nutrition, University of KwaZulu-Natal, Pietermaritzburg, South Africa \\ ${ }^{3}$ Centre for Statistical Analyses, Stellenbosch University, Stellenbosch, South Africa
}

Corresponding author: Y Smit (yolandes@sun.ac.za)

\begin{abstract}
Background. Unhealthy food choices made by mothers can impact negatively on child health and may lead to unhealthy eating behaviours that persist into adulthood. Choosing food is a complex process influenced by many factors.

Objectives. To determine the factors that influence mothers' food choices and to investigate barriers to purchasing healthy food.

Methods. A cross-sectional, descriptive study, with an analytical component, was conducted. Mothers $(N=476)$ were recruited from three randomly selected primary schools, from a low, middle and high quintile. A self-administered questionnaire was used to collect data on demographics, knowledge, attitude and practices of mothers. Six focus groups (FG) (two per school) were conducted to investigate the factors that prevent mothers from making healthy dietary decisions.

Results. The mean nutrition knowledge score for the group was $68.6 \%$. Nutrition knowledge was significantly lower $(p<0.01)$ in mothers from the lower quintile school (64.0\%). Primary factors influencing food purchases were cost (60\%), nutritional value (37\%) and time constraints (29\%). Primary sources of nutrition information included magazines and health professionals at $62 \%$ and $44 \%$, respectively. Time constraints resulted in mothers purchasing convenience foods more often $(p=0.001)$. The main barriers identified were mixed media messages, the school environments and supermarket layouts.

Conclusion. Nutrition education campaigns should include practical advice, e.g. the preparation of economical, wholesome meals. Policymakers should monitor increasing prices of healthy foods. School and supermarket environments, as well as the food industry, can play a pivotal role in facilitating mothers to make healthy food choices.
\end{abstract}

S Afr J Child Health 2017;11(3):129-134. DOI:10.7196/SAJCH.2017.v11i3.1292

Mothers of young children have a primary influence and control over the food their children eat and have access to. ${ }^{[1]}$ Their role is fundamental in promoting a healthy lifestyle and behaviour in children. ${ }^{[2-4]}$ Dietary habits, including healthy food choices acquired during childhood, often persist into adulthood and lay the foundation for adult health and quality of life. ${ }^{[5,6]}$ Childhood obesity is a growing phenomenon in South Africa, is a risk factor for non-communicable diseases (NCDs), and often tracks into adulthood, which is associated with growing up in an obesogenic environment. ${ }^{[5,7]}$

Although the home environment is the logical place in which to foster healthy eating habits, studies have shown that food choices are complex and influenced by several factors including knowledge, socioeconomic status, cost, taste, child preference, urbanisation, and culture. ${ }^{[3,8,9]}$ These factors ultimately impact on the food that is available at home. The Metro North Education District (MNED) in the Western Cape (WC) Province, South Africa, is an urban district with diverse living conditions ranging from wealthy suburbs to underdeveloped informal urban areas. Diverse sociodemographic profiles are prominent. It is therefore important to recognise the impact that socioeconomic status can have on food choices made by mothers. Nutrition research should not lose touch with reality and ought to be tailored for specific target audiences, including more vulnerable, lowincome groups. ${ }^{[10,11]}$

A better understanding of these elements can impact future health education strategies and social marketing campaigns targeting mothers and children's food choices, and may play a role in curbing the growing epidemic of childhood obesity. The objectives of the study were to: (i) investigate the factors that influence food choices of mothers with children attending primary schools in the MNED of the WP; and (ii) to identify barriers to making healthy food choices.

\section{Methods}

A mixed-method study design employing triangulation of data was conducted. A self-administered questionnaire (SAQ) was used to collect demographic data, data related to factors and barriers influencing food choices, and to identify mothers for focus groups (FGs) to further explore these factors and barriers. Approvals to conduct the study were obtained from the Health Research Ethics Committee of Stellenbosch University (S/3/10/210), the Western Cape Education Department (WCED) and the respective school principals.

\section{Sampling of schools}

A list of schools in the MNED was obtained from the WCED website. ${ }^{[12]}$ Public primary schools were stratified into the five national quintiles (NQ). The excel random generation function was used to randomly select one school from each quintile. Quintiles 1 and 5 represented lower and higher socioeconomic groups, respectively. Schools from quintile 1 to 3 were grouped together as they qualified for exemption of school fees and represented disadvantaged communities. Hence, 3 schools were randomly selected; school A (NQ 1 - 3), school B (NQ 4) and school C (NQ 5). Two schools were selected for the pilot study, 1 school from NQ 1 to 3 and 1 from NQ 4. Schools were contacted by the researcher to gain permission to conduct the study. If it was not granted, the random selection process was repeated. 


\section{Sampling of mothers}

Primary schools included learners from grades 1 to 7 . Two classes per grade were randomly selected. Children received a SAQ to take home to their mothers. Since older children have a greater influence on mothers' decision-making, to keep the sample homogenous, children who had siblings in high school were excluded from this study. ${ }^{[13]}$ To recruit FG participants, the last page of the questionnaire included a tear-off slip for mothers to indicate their willingness to participate in a FG. All mothers who supplied their contact details were contacted telephonically and depending on their willingness or availability, were invited to participate in the FG.

\section{Preparation for the study}

Prior to the study, the researcher visited the school principals to explain both the purpose of the study, and to discuss the language proficiency of the parents. School principals confirmed that the language used for communication with parents was Afrikaans and English. The study was piloted at an NQ 3 and an NQ 4 school. These schools did not form part of the main study. During the pilot study, the face validity of the questionnaire was assessed and feedback from the parents relating to readability and understanding of the SAQ was received to ensure that participants could fill in the questionnaire. ${ }^{[14,15]}$ Content validity was evaluated by three dietitians with experience in the relevant field. ${ }^{[14,15]}$

\section{Data collection tools}

\section{Phase 1: Self-administered questionnaire}

The SAQ was developed to identify factors influencing food choices based on an existing, validated, nutrition knowledge questionnaire for adults. ${ }^{[16]}$ This paper reports results pertaining to section (i) demographics, (ii) nutrition knowledge and ( $v$ ) barriers.

Questionnaires were distributed to the children in unsealed envelopes. Parents were asked to return the questionnaire in the sealed envelope. Consent forms for participation in the main study were provided in duplicate - one copy for the parents' reference and the other to be returned to the school with the completed questionnaire. Consent forms were available in Afrikaans and English and the researcher's contact details were provided in case participants had any queries. Questionnaires were coded (A, B or C) in order to identify the school they originated from and for data entry and coding purposes.

\section{Phase 2: Focus groups}

Thirty-seven mothers participated in the FG discussions (FGDs) to obtain a deeper understanding of the factors influencing food choices and to explore barriers to making healthy food choices. Participation in the FGs varied from 5 to 10 participants per FG. ${ }^{[17]}$ The discussions were conducted in a pre-arranged, suitable, school-based venue. One female researcher used a discussion guide to facilitate the FGs. Ten questions were included to explore the influence of knowledge, employment status, family preference, barriers and school environment to making healthy food choices. A list of probes, e.g. 'tell me more', 'why do you feel that way?', and 'explain further', were included in the discussion guide. An observer who was a qualified nutritionist, made notes regarding participant interaction and nonverbal cues. No language barriers were experienced during the FGDs. The researcher translated questions or replies into either Afrikaans or English if there was a need.

The researcher ended off the discussion by asking the participants if they had additional comments and then summarised the main responses.

\section{Data analysis}

Microsoft Excel 2007 was used for data entry and STATISTICA version 12 (StatSoft Inc., USA) for data analysis. Summary statistics were used to describe sample characteristics. Independent variables were compared with appropriate analysis of variance (ANOVA). Bonferroni multiple comparisons identified significant differences between groups. Dependent variables were compared with independent variables using the Mann-Whitney or Kruskal-Wallis tests. Relations between nominal variables were investigated with contingency tables and likelihood ratio $\chi^{2}$ tests.

Voice recordings were transcribed verbatim by one researcher and reread several times to ensure accuracy of the transcriptions. Thematic content analysis was performed by the same researcher. Major themes were identified based on the study objectives, manually coded and a code list was compiled. Quotes pertaining to each theme were transferred from the original text and copied to the most applicable code. New emerging themes were also deduced from the transcriptions. ${ }^{[15,18]}$

\section{Results}

A $50 \%$ response rate yielded a study sample of $N=476$. Sociodemographic characteristics of the study sample were defined according to the SAQ (Table 1). The mean (SD) age of participants was 37.45 (7.07). Six FGs $(N=37)$ were conducted, two per school. Participation in the FG was as follows: 16 participants from NQ $1-3,11$ participants from NQ 4, and 10 participants from NQ 5. Mothers were mixed race $(n=34)$ or black $(n=3)$.

\section{Nutrition knowledge}

Participants were asked a series of nutrition-related questions (Table 2). The questions with the lowest mean scores were 'white bread is healthier when it is toasted', 'low fat products contain less than $3 \mathrm{~g}$ fat per $100 \mathrm{~g}$ ' and 'brown sugar and honey is healthier than white sugar.'

The nutrition knowledge of mothers from school A (64.0\%) was significantly lower $(p<0.01)$ compared with mothers from schools B (70.3\%) and C (74\%). The mean (SD) nutrition knowledge score for the whole group $(N=476)$ was $68.6 \%$.

During the FGs, all mothers from the lower socioeconomic group agreed that nutrition knowledge could influence food choices. Mothers from the higher socioeconomic groups agreed that other factors such as habit, tradition or children's preferences also influence food choice.

Inadequate nutrition knowledge resulted in misperceptions regarding healthy food choices. The majority of mothers from schools A and B were of the opinion that 'brown sugar is healthier than white sugar' and that they 'have to buy it for their kids'. Mothers from the lower socioeconomic group seemed to be aware that carbonated beverages have a high sugar content and explained that they would rather opt for a cool drink that 'can be diluted with water or ice because it absorbs the sugar' and is an alternative to drinking water. However, even though they were aware of the high sugar content, the gas in the carbonated drinks was perceived as the main reason for making them unhealthy, thereby placing less emphasis on the high sugar content.

\section{Sources of nutrition information}

Mothers source nutrition information from various platforms (Fig. 1). During FGs, the workplace, hospitals, child-care centres and clinics were mentioned as additional sources of nutrition information by mothers from schools A and B. Only mothers from school C indicated that they used the internet as a source of information. Mothers from school A explained that they listened to advice given by nurses at clinics and applied the healthy eating guidelines to themselves and their families. Most mothers were aware of the nutritional information on food products; however, they all agreed that it did not influence their purchasing decisions. Mothers from schools B and Chad the perception that the products with logos on are more expensive. Despite any differences, all of the FG participants expressed the need to understand and use the available nutrition information on food labels to guide their food choices.

\section{Other factors influencing food choice}

Numerous important factors influence the choices mothers make when buying food (Fig. 2). The cost of a product was significantly more important $(p<0.001)$ for mothers from school A, $(72 \% ; n=145)$ compared with mothers from schools B and C, $(56 \% ; n=83)$ and $(50 \% ; n=64)$, 
Table 1. Sociodemographic information of mothers $(N=476)$

\begin{tabular}{|c|c|c|c|c|}
\hline & $\begin{array}{l}\text { All schools } \\
\text { (NQ 1 - 5); } \\
N=476, \\
n(\%)^{*}\end{array}$ & $\begin{array}{l}\text { School A } \\
\text { (NQ 1 - 3); } \\
n=202, \\
n(\%)\end{array}$ & $\begin{array}{l}\text { School B } \\
\text { (NQ 4); } \\
n=147 \\
n(\%)\end{array}$ & $\begin{array}{l}\text { School C } \\
\text { (NQ 5); } \\
n=127, \\
n(\%)\end{array}$ \\
\hline \multicolumn{5}{|l|}{ Relationship to child } \\
\hline Mother & $447(94)$ & $188(93)$ & $133(90)$ & $126(99)$ \\
\hline Grandmother & $8(2)$ & $5(2.5)$ & $2(1.3)$ & $1(0.01)$ \\
\hline Foster mother & $21(4)$ & $9(4.5)$ & $12(8)$ & $0(0)$ \\
\hline Race & $(N=475)$ & $(n=202)$ & $(n=146)$ & $(n=127)$ \\
\hline Black & $52(11)$ & $21(10.4)$ & $17(12)$ & $14(11)$ \\
\hline Coloured & $406(85)$ & $180(89.1)$ & $117(80)$ & $109(86)$ \\
\hline Indian & $4(0.1)$ & $1(0.5)$ & $0\left(\begin{array}{lll}0 & 0\end{array}\right)$ & $3(2.4)$ \\
\hline White & $13(3)$ & $0(0.0)$ & $12(8)$ & $1(0.01)$ \\
\hline Employment status & $(N=467)$ & $(n=198)$ & $(n=143)$ & $(n=126)$ \\
\hline Working & $316(68)$ & $105(53)$ & $109(76)$ & $102(81)$ \\
\hline Not working & $151(32)$ & $93(47)$ & $34(24)$ & $24(19)$ \\
\hline Level of education & $(N=470)$ & $(n=198)$ & $(n=145)$ & $(n=127)$ \\
\hline Grade $\leq 7$ & $60(13)$ & $52(26)$ & $8(6)$ & $0(0)$ \\
\hline Grade $8-11$ & $154(33)$ & $108(55)$ & $37(25)$ & $9(7)$ \\
\hline Grade 12 & $146(31)$ & $32(16)$ & $69(48)$ & $45(35)$ \\
\hline Diploma or higher degree & $110(23)$ & $6(3)$ & $31(21)$ & $73(57)$ \\
\hline Level of income (ZAR per month) & $(N=435)$ & $(n=181)$ & $(n=133)$ & $(n=121)$ \\
\hline$<1000$ & $76(17)$ & $65(36)$ & $11(8)$ & $0(0)$ \\
\hline $1001-2500$ & $71(16)$ & $58(32)$ & $13(9)$ & $0(0)$ \\
\hline $2501-3500$ & $33(8)$ & $26(14)$ & $7(5)$ & $0(0)$ \\
\hline $3501-5500$ & $47(11)$ & $19(11)$ & $19(14)$ & $9(7)$ \\
\hline $5501-9000$ & $44(10)$ & $11(6)$ & $21(16)$ & $12(10)$ \\
\hline $9001-12500$ & $39(9)$ & $2(1)$ & $21(16)$ & $16(13)$ \\
\hline $12501-16500$ & $38(9)$ & $0(0)$ & $14(11)$ & $24(19)$ \\
\hline$>16500$ & $87(20)$ & $0(0)$ & $27(20)$ & $60(46)$ \\
\hline
\end{tabular}

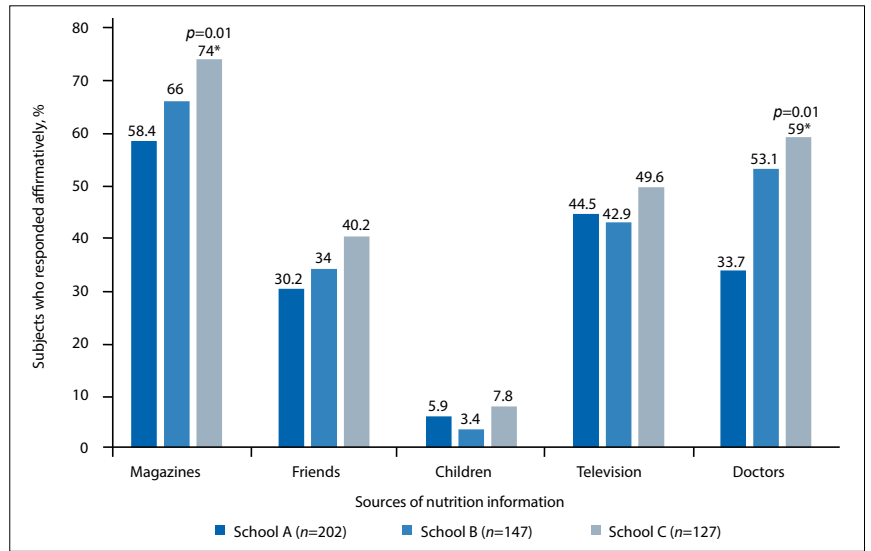

Fig. 1. Sources of nutrition information as indicated by mothers from 3 primary schools representing different socioeconomic groups $\left(\mathrm{N}=476 ;{ }^{*} \mathrm{p}<0.05, \chi^{2}\right.$ statistics).

respectively. During the FGs, all mothers agreed that they shop where the bargains are and would rather choose products that are on special.

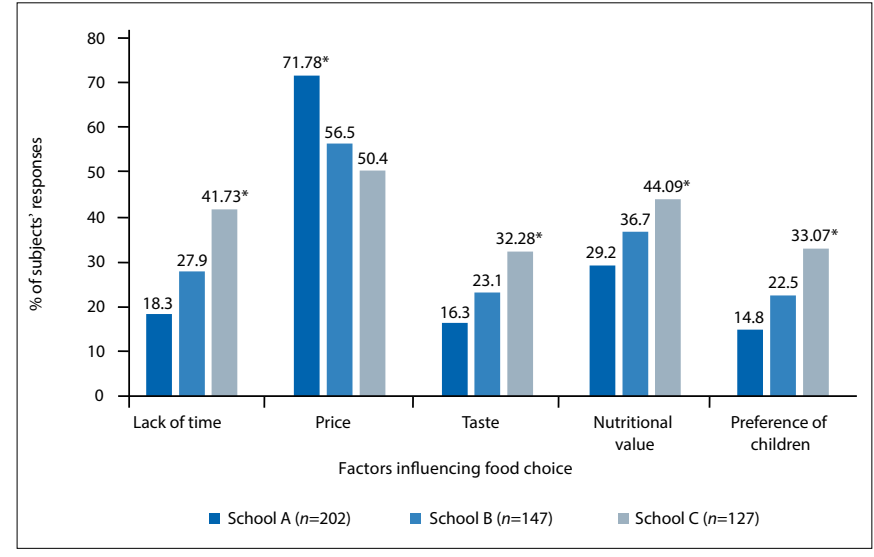

Fig. 2. Comparison of factors influencing food choices of mothers from 3 primary schools representing different socioeconomic groups $\left(\mathrm{N}=476,{ }^{*} \mathrm{p}<0.05, \chi^{2}\right.$ statistics).

Mothers from the lower socioeconomic group expressed their concern regarding the high cost of the fruit and vegetables that they buy from 
Table 2. Percentage score of nutrition knowledge questions answered correctly $(N=476)$

\begin{tabular}{|c|c|c|c|c|}
\hline Statement & $\begin{array}{l}\text { All schools } \\
(N=476), \\
n(\%)\end{array}$ & $\begin{array}{l}\text { School A } \\
(n=202), \\
n(\%)\end{array}$ & $\begin{array}{l}\text { School B } \\
(n=147), \\
n(\%)\end{array}$ & $\begin{array}{l}\text { School C } \\
(n=127), \\
n(\%)\end{array}$ \\
\hline White bread is healthier when toasted & $197(41.3)$ & $52(25.7)$ & $68(46.3)$ & $77(60.6)$ \\
\hline Growing children need a lot of sugar & $315(66.1)$ & $90(44.5)$ & $115(78.2)$ & $110(86.6)$ \\
\hline Children need to eat fruit and vegetables daily & $459(96.4)$ & $193(95.5)$ & $143(97.2)$ & $123(96.8)$ \\
\hline $\begin{array}{l}\text { If children eat a healthy diet there is no need for them } \\
\text { exercise }\end{array}$ & $430(90.3)$ & $167(82.6)$ & $138(93.8)$ & $125(98.4)$ \\
\hline A glass of fruit juice is healthier than a fresh fruit & $365(76.6)$ & $130(64.3)$ & $122(82.9)$ & $113(88.9)$ \\
\hline Fruit and vegetables are fat-free items & $309(64.9)$ & $146(72.2)$ & $87(59.8)$ & $76(59.0)$ \\
\hline Red meat is a good source of iron & $311(65.3)$ & $118(58.4)$ & $100(73.2)$ & $93(73.2)$ \\
\hline Baked beans are a good source of protein & $361(75.8)$ & $153(75.7)$ & $106(80.3)$ & $102(80.3)$ \\
\hline Fried eggs are healthier than boiled eggs & $440(92.4)$ & $186(92.0)$ & $134(94.4)$ & $120(94.4)$ \\
\hline Low-fat products contain $<3 \mathrm{~g}$ fat per $100 \mathrm{~g}$ & $178(37.3)$ & $84(41.5)$ & $53(32.2)$ & $41(32.2)$ \\
\hline Gas cooldrinks are healthy drinks & $456(95.8)$ & $188(93.0)$ & $144(97.6)$ & $124(97.6)$ \\
\hline Brown sugar and honey are healthier than white sugar & $22(46.2)$ & $11(54.4)$ & $3(20.4)$ & $8(62.9)$ \\
\hline Coffee creamers are just as healthy as milk & $406(85.2)$ & $164(81.18)$ & $131(89.1)$ & $111(87.4)$ \\
\hline
\end{tabular}

Table 3. Comparison of responses from mothers at different schools pertaining to barriers to making healthy food choices and food preparation practices

\begin{tabular}{|c|c|c|c|c|c|c|c|}
\hline Barrier & School & $n$ & $\begin{array}{l}\text { Strongly } \\
\text { disagree, } \\
n(\%)\end{array}$ & $\begin{array}{l}\text { Disagree, } \\
n(\%)\end{array}$ & $\begin{array}{l}\text { Agree, } \\
n(\%)\end{array}$ & $\begin{array}{l}\text { Strongly } \\
\text { agree, } \\
n(\%)\end{array}$ & $p$-value \\
\hline \multirow{4}{*}{$\begin{array}{l}\text { I do not know how to prepare } \\
\text { healthy meals }(N=470)\end{array}$} & A & 198 & 77 (38.9) & $96(48.4)$ & $24(12.1)$ & 10.5 & \multirow[t]{4}{*}{$0.32^{*}$} \\
\hline & B & 146 & $59(40.4)$ & $73(50)$ & $11(7.5)$ & $3(2.0)$ & \\
\hline & $\mathrm{C}$ & 126 & $61(48.4)$ & $51(40.4)$ & $13(10.3)$ & $1(0.8)$ & \\
\hline & Average & & $197(42.5)$ & $220(46.2)$ & $48(10.2)$ & $5(1.1)$ & \\
\hline \multirow{4}{*}{$\begin{array}{l}\text { Fast food shops close to home } \\
(N=471)\end{array}$} & A & 199 & 99 (49.8) & $87(43.7)$ & $11(5.5)$ & $2(1.0)$ & \multirow[t]{4}{*}{$0.30^{*}$} \\
\hline & B & 146 & $75(51.4)$ & $67(45.8)$ & $2(1.3)$ & $2(1.3)$ & \\
\hline & $\mathrm{C}$ & 126 & $64(50.8)$ & $55(43.6)$ & $3(2.3)$ & $4(3.1)$ & \\
\hline & Average & & $238(50.6)$ & $209(44.3)$ & $16(3.3)$ & $8(1.6)$ & \\
\hline \multirow{4}{*}{$\begin{array}{l}\text { I use oil regularly when prepa- } \\
\text { ring meals } \\
(N=472)\end{array}$} & A & 199 & $20(10.0)$ & $54(27.1)$ & $114(57.3)$ & $11(5.5)$ & \multirow[t]{4}{*}{$0.02^{\dagger \ddagger}$} \\
\hline & B & 147 & $16(10.8)$ & $54(36.7)$ & $70(47.6)$ & $7(4.8)$ & \\
\hline & $\mathrm{C}$ & 126 & $12(9.5)$ & $58(46.0)$ & $52(41.3)$ & $4(3.2)$ & \\
\hline & Average & & $48(10.2)$ & $66(35.2)$ & $236(50)$ & $22(4.0)$ & \\
\hline \multirow{4}{*}{$\begin{array}{l}\text { I add sugar and margarine to } \\
\text { vegetables to make them tasty } \\
(N=474)\end{array}$} & A & 201 & $15(7.5)$ & $55(27.3)$ & $121(60.2)$ & $10(4.9)$ & \multirow[t]{4}{*}{$0.01^{\dagger \varsigma}$} \\
\hline & B & 147 & $18(12.2)$ & $52(35.3)$ & $75(51)$ & $2(1.2)$ & \\
\hline & $\mathrm{C}$ & 126 & $13(10.3)$ & $48(38.1)$ & $58(46)$ & $7(5.5)$ & \\
\hline & Average & & $46(9.7)$ & $155(37.2)$ & $254(53.6)$ & $19(4.0)$ & \\
\hline
\end{tabular}

informal vendors, sometimes the only suppliers they have access to. Furthermore, these mothers agreed that unhealthy food options such as sweets and chips are more affordable when compared with purchasing fresh fruit or healthy food.

Significantly more mothers $(p=0.02)$ from school C $(44 \% ; n=56)$ listed nutritional value as an influencing factor compared with mothers from school A (29\%; $n=59)$. Information deduced from the FGs indicated that mothers, regardless of their socioeconomic status, viewed fruit and vegetables as an essential part of a healthy diet. They also mentioned low- fat products and foods containing roughage as being healthier, confirming that mothers were aware of the nutritional value of these foods.

More mothers $(p=0.000)$ from school C $(42 \% ; n=53)$ reported that a lack of time influenced their food choices compared with mothers from school A $(18 \% ; n=37)$ and mothers from school B $(27 \% ; n=41)$. During the FGs, mothers from school $\mathrm{C}$, the higher socioeconomic group, explained that time constraints, mostly as a result of them working, resulted in opting for time-saving convenience options, even if they were not the healthiest. 
Table 4. Comparison of the responses of mothers from different schools towards the statement: 'The messages through TV and radio influence my food choice $(N=473)$

\begin{tabular}{lllll} 
& $\begin{array}{l}\text { Strongly } \\
\text { disagree, } \boldsymbol{n}(\%)\end{array}$ & $\begin{array}{l}\text { Disagree, } \\
\boldsymbol{n}(\%)\end{array}$ & $\begin{array}{l}\text { Agree, } \\
\boldsymbol{n}(\%)\end{array}$ & \multicolumn{1}{c}{$\begin{array}{l}\text { Strongly agree, } \\
\boldsymbol{n}(\%)\end{array}$} \\
\hline School A $(n=201)$ & $26(12.9)$ & $59(29.4)$ & $94(46.7)$ & $22(10.9)$ \\
School B $(n=145)$ & $10(6.9)$ & $50(34.5)$ & $74(51.0)$ & $11(7.9)$ \\
School C $(n=127)$ & $9(7.1)$ & $48(37.8)$ & $57(44.9)$ & $13(10.2)$ \\
${ }^{*} p>0.05 \chi^{2}$ statistics indicate no statistically significant difference. & & &
\end{tabular}

Taste and child preference were significantly $(p=0.003)$ more important factors for mothers from school C $(32.3 \% ; n=41)$ and $(33.1 \%, n=42)$, respectively. During FGs, mothers from school A felt strongly that children must eat what is served compared with mothers from school C who said, 'I buy what my kids want even if I know it is not the healthiest option.

\section{Barriers to making healthy food choices}

A lack of cooking skills and accessibility to numerous fast-food outlets were not viewed as a barrier when food choices were made (Table 3). However, more than half of the study sample that completed the SAQ indicated that they regularly made use of unhealthy meal preparation methods through the addition of unhealthy ingredients like oil, sugar and margarine. Three main barriers identified during the FGs are discussed below.

\section{Inconsistent media messages}

Several mothers from school C voiced their frustration with the mixed messages resulting in confusion. They explained that children are vulnerable, easy to influence and aware of marketing strategies. More than half $(57 \% ; n=271)$ of the participants agreed that media messages influence their food choices (Table 4).

\section{School environment}

School tuck shops (a small kiosk providing snacks on the school premises) were discussed during the FGs. Schools B and C had tuck shops and mothers from school A reported that informal vendors would sell chips and sweets outside the school premises. Almost all of the mothers agreed that tuck shops and informal vendors sell predominantly unhealthy food, but were unsure if fresh fruit was sold at the tuck shop. Some mothers expressed the desire to be involved in deciding what was sold at tuck shops. All mothers agreed that schools should create more awareness and encourage children to bring more healthy food to school.

All FG participants acknowledged the powerful impact that teachers have on their children, because the children idealised their teachers. Mothers from the lower socioeconomic group agreed that it was the school's responsibility to teach children about healthy eating.

\section{Supermarket layout}

Mothers from schools B and C agreed that if aisles with healthier options were more prominently positioned and convenient to access, it would assist them and their children to make healthier food choices. Mothers from school A, who often bought food from spaza shops, explained that 'if fruit and vegetables were more visible, the children might also choose to buy it more often.

\section{Discussion}

Higher levels of parental education were positively associated with higher nutrition knowledge scores. ${ }^{[10,11]}$ In turn, higher levels of nutrition knowledge were positively associated with healthy diets. ${ }^{[16]}$ This study identified gaps in knowledge related to fibre, fat and sugar intake, which could potentially have a negative impact on childhood health. Diets low in fibre and high in fat and sugar are indicators of the nutrition transition taking place in South Africa. ${ }^{[19]}$ Questions with the best scores directly related to the messages conveyed through the South African Food-Based Dietary Guidelines (FBDG). ${ }^{[20]}$

Even though mothers knew that fried foods were less healthy, they still used oil and margarine regularly in the preparation of meals. This strengthens the notion that knowledge does not necessarily translate into healthy food choices or preparation practices. ${ }^{[21}$ This study emphasised the importance of nutrition education, especially for mothers from lower socioeconomic groups. Furthermore, the study found that the media was a powerful medium to convey scientifically accurate information to the lay public and should be better utilised ${ }^{[22]}$ The cost of food was identified as the strongest determining factor influencing food choices, regardless of the school quintile. The effect of food cost on food choices and healthy eating cannot be underestimated; it calls for drastic measures to be implemented by the SA government and the food industry to curb the increasing cost of healthy food. Less healthy, energy-dense food is more affordable, making it a more desirable purchasing option, especially among lower socioeconomic groups. ${ }^{[10,23,24]}$ It is therefore evident that it is not only the high cost of healthy food, but also the affordability of unhealthy food that seems to be a barrier when making healthier food choices. $^{[23]}$

A third of the study sample listed nutritional value as a factor influencing food choice compared with the $14.3 \%$ of participants in the SANHANES-1 study. ${ }^{[8]}$ It is concerning that mothers potentially do not have adequate nutrition knowledge to identify foods with high nutritional value, as identified by the knowledge questions and FGs in this study. Similar to the findings of Machin et al., ${ }^{[25]}$ mothers found it difficult to interpret nutrition information tables, even though they expressed a need to understand them. Mothers in this study therefore did not benefit optimally from this source of information. Simplified nutrition labels or logos might be more effective in influencing food choices, especially among those individuals in lower-income groups.

Vastly higher percentages of mothers, although significantly different between the three schools (Fig. 2), reported that time constraints influenced their food choices, compared with the $9.6 \%$ in the SANHANES-1 study. ${ }^{[7]}$ Time constraints resulted in the regular purchases of convenience foods, especially in school C, the quintile 5 school that also had a higher complement of working mothers. Unfortunately, these foods are often high in fat and sugar and children become accustomed to them, hence developing a preference. ${ }^{[26,27]}$ This could result in the younger generations acquiring fewer cooking skills from their mothers and, in turn, a reliance on convenience foods.

Nutritional advice often centres around what to eat, with less emphasis being placed on how to incorporate the advice into a busy lifestyle. ${ }^{[2]}$ Not only is there a need for healthier pre-prepared and convenience meals, but also for the education of mothers on ways to prepare quickand-easy nutritious homemade meals. The food industry has responded and capitalised on this need, but the majority of options still focus on convenience and not on health. ${ }^{[27,28]}$

The value of changing supermarket layout to enhance the visibility of healthier items justifies further exploration. Participants in a study conducted by Zacchary et al ${ }^{[29]}$ suggested having taste test sections to increase consumer confidence in a product. By changing supermarket layout, the principle of making healthier choices the easiest choice, can be supported and implemented. ${ }^{[30]}$ In addition, creating a healthy school 
environment and utilising teachers as role models and advocates for healthy eating can influence children's attitudes towards healthy eating, creating a positive spillover into the home environment. ${ }^{[31]}$ Increased parental involvement in decision-making regarding the food items sold at school tuck shops can ensure that healthy nutrition principles are implemented consistently at school and in the home environment. ${ }^{[3]}$

This study was the first in SA that focused specifically on mothers of primary school children, and comparing NQs with each other. The study provided new insights into the needs and challenges that exist between different socioeconomic groups, strengthening the notion that nutrition education and health promotion should be tailor-made for diverse groups. These results could be of value when developing interventions that involve mothers as important change agents, aimed at the prevention of childhood obesity.

\section{Study limitations}

The sociodemographic distribution of race was not representative, as the study sample included a limited number of white and black participants. The researchers acknowledge the potential of acquiescence and social desirability bias with FG participants, as well as the Hawthorne effect with the mothers who completed the SAQ. This may have influenced the extrapolation and generalisations of the study findings.

\section{Conclusion}

Greater emphasis should be placed on imparting basic nutrition knowledge to diverse target audiences. This includes empowering mothers to interpret food labels and demonstrating healthy and economical food preparation techniques. The school environment can be used effectively to change children's perceptions regarding healthy food, and support mothers to implement their nutrition knowledge in the home environment. This justifies further investigations to effectively identify specific target groups within the larger public. ${ }^{[10]}$

Acknowledgements. Participants, school principals and the Harry Crossley Foundation.

Author contributions. YS did the primary data collection and analyses. DN did the statistical analyses.

Funding. The Harry Crossley Foundation.

Conflicts of interest. None.

1. Johnson CM, Sharkey JR, Dean WR, Kubena KS. It's who I am and what I eat. Mothers' food-related identities in family food choice. Appetite 2011;57(1):220228. https://doi.org/10.1016/j.appet.2011.04.025

2. Lindsay AC, Sussner KM, Kim J, Gortmaker S. The role of parents in preventing childhood obesity. Future of Children 2006;16(1):169-186. https:// doi.org/10.1353/foc. 2006.0006

3. Patrick H, Nicklas TA. A review of family and social determinants of children's eating patterns and diet quality. J Am Coll Nutr 2005;24(2):83-92. https://doi. org /10.1080/07315724.2005.10719448

4. Scaglioni S, Arrizza G, Vecchi F, Tedeschi S. Factors of children's eating behavior. Am J Clin Nutr 2011;94(6):2006s-2011s. https://doi.org/10.3945/ ajcn.110.001685

5. Black RE, Victora CG, Walker SP, et al. Maternal and child undernutrition and overweight in low-income and middle-income countries. Lancet 2013;382(9890):427-451. https://doi.org/10.1016/s0140-6736(13)60937-x

6. Nossle C. Childhood obesity on the increase. The Mercury. http://iol, co.za/mercury/childhood-obesity-in-the-increase-1.1213585 (accessed 12 September 2013).

7. Schonfeldt HC, Gibson N. Healthy eating in the South African context. J Food Comp Anal 2009;22:68-73. https://doi.org/10.1016/j.jfca.2009.01.005

8. Shisana O, Labadarios D, Rehle T, et al., and the SANHANES-1 Team. South African National Health and Nutrition Examination Survey (SANHANES-1): 2014 Edition. Cape Town: HSRC Press, 2014. http://www.hsrcpress.ac.za/ product.php? productid $=2314 \&$ cat $=0 \&$ page $=1 \&$ featured $\&$ freedownload $=1$ (accessed 12 September 2014).
9. Cowburn G, Stockley L. Consumer understanding and use of nutrition labeling: a systematic review. Public Health Nutr 2005;8(1):21-28. https://doi. org / 10.1079/phn2004666

10. Darmon N, Drewnowski A. Does social class predict diet quality? Am J Clin Nutr 2008;87(5):1107-1117.

11. Turrell G, Kavanagh AM. Socio-economic pathways to diet: modeling the association between socio-economic position and food purchasing behavior. Public Health Nutr 2005;9(3):375-383. https://doi.org/10.1079/phn2006850

12. Western Cape Education Department website. Find-A-School. http://wcedemis. pgwc.gov.za/wced/findaschool.html (accessed 12 October 2013).

13. Mangleburg TF. Children's influence in purchase decisions: A review and critique. Adv Consum Res 1990;17:813-825.

14. Gleason PM, Harris J, Sheaan PM, Boushey CJ, Bruemmer B. Publishing nutrition research: Validity, reliability and diagnostic test assessment in nutrition-related research. J Am Diet Assoc 2010;110:409-419. https://doi. org/10.1016/j.jada.2009.11.022

15. Skinner D. Qualitative research methodology: An introduction. In: Joubert G, Ehrlich R, eds. Epidemiology: A Research Manual for South Africa. Cape Town: Oxford University Press; 2008:318-326.

16. Parmenter K, Wardle J. Development of a general nutrition knowledge questionnaire for adults. Europ J Clin Nutr 1999;53:298-308. https://doi. org/10.1038/sj.ejcn.1600726

17. Rabiee F. Focus group interviews and data analysis. Proceedings of the Nutrition Society. 2004;63:655-660. https://doi.org/10.1079/pns2004399

18. Mitchell K, Branigan P. Using focus groups to evaluate health promotion interventions. Health Educ 2000;100(6):261-268. https://doi. org/10.1108/09654280010354887

19. Abrahams Z, Mchisa Z, Steyn NP. Diet and mortality rates in Sub-Saharan Africa: Stages of the nutrition transition. BMC Public Health 2011;11(1):801. https://doi.org/10.1186/1471-2458-11-801

20. Vorster HH. Badham JB, Venter CS. An introduction to the revised food-based dietary guidelines for South Africa. S Afr J Clin Nutr 2013;26(3):5-12.

21. Wardle J, Parmenter K, Waller J. Nutrition knowledge and food intake. Appetite 2000;34:268-275. https://doi.org/10.1006/appe.1999.0311

22. Charlton KE, Brewitt P, Bourne LT. Sources and credibility of nutrition information among black urban South African women, with a focus on messages related to obesity. Public Health Nutr 2004;7(6):808-811. https://doi. org/10.1079/phn2004611

23. Temple NJ, Steyn NP. The cost of a healthy diet: A South African perspective. Nutrition 2011;27(5):505-508. https://doi.org/10.1016/j.nut.2010.09.005

24. Fitzgerald N, Spaccarotella K. Barriers to a healthy lifestyle: From individual to public policy - an ecological perspective. J Extension 2009;47(1):1-8.

25. Machín L, Giménez A, Curutchet MR, Martinez J, Ares G. Motives underlying food choice for children and perception of nutritional information among low-income mothers in a Latin American country. J Nutr Educ Behav 2016;48(7):478-485. https:// doi.org/10.1016/j.jneb.2016.04.396

26. Slater J, Sevenhuysen G, Edginton B, O’Nell J. Trying to make it all come together: structuration and employed mothers' experience of family food provisioning in Canada. Health Prom Int 2012;27(3):405-415. https://doi.org/10.1093/heapro/dar037

27. Devine CM, Jastran M, Jabs JA, Wethington E, Farrell TJ, Bisogni CA. A lot of sacrifices: Work-family spillover and the food choice coping strategies of low wage employed parents. Soc Sci Med 2006;63(10):2591-2603. https://doi.org/10.1016/j. socscimed.2006.06.029https://doi.org/10.1016/j.socscimed.2006.06.029

28. Jabs J, Devine CM. Time scarcity and food choices: An overview. Appetite 2006;47(2):196-204. https://doi.org/10.1016/j.appet.2006.02.014

29. Zachary DA, Palmer AM, Beckham SW, Surken PJ. A Framework for understanding grocery purchasing in a low-income urban environment. Qual Health Res 2013;35(5):665-678. https://doi.org/10.1177/1049732313479451

30. World Health Organization. Milestones in Health Promotion. Statements from Global Conferences. Geneva. Switzerland. 2009. http://who.int/healthpromotion/ Milestones-Health-Promotion-05022010.pdf (accessed 12 September 2013).

31. Global Nutrition Report. From Promise to Practise. UNICEF DATA 2016. https://data.unicef.org/wp-content/uploads/2016/06/130565-1.pdf_http://dx.doi. org/10.2499/9780896295841.

32. Wiles NL, Green JM, Veldsman FJ. Tuck shop purchasing practices of Grade 4 learners in Pietermaritzburg and childhood overweight and obesity. S Afr J Clin Nutr 2013;26(1):37-42. https://doi.org/10.1080/16070658.2013.11734438 